\title{
The Ability to Identify Early Apical Pathology: A Comparison between UK's General Dental Practitioners and Endodontists
}

\author{
Ibtesam Orafi \\ The School of Dentistry, Benghazi University, Libya
}

Copyright (C) 2015 by authors, all rights reserved. Authors agree that this article remains permanently open access under the terms of the Creative Commons Attribution License 4.0 International License

\begin{abstract}
Objectives: To investigate the ability of endodontists and general dental practitioners (GDPs) to interpret early periapical pathology and to examine effect of age, undergraduate education and attendance at courses upon radiographic interpretation. The hypothesis was that there would be no significant difference between GDPs and endodontists. Methods: General dental practitioners $(n=603)$ and endodontists $(n=132)$ had access to high quality images of 12 periapical radiographs. The images had been previously scanned to obtain the same resolution as the original radiograph. Each was presented to observers as an exact replica of the size of a size 2 periapical film. Six radiographs demonstrated the presence of an early periapical lesion on a specific tooth whilst the remaining six radiographs showed normal periodontium. Each radiograph was printed on high quality paper. Each participant was asked to examine a specific tooth for the presence/absence of apical pathosis. Results: The mean sensitivity and specificity for the endodontists was 0.65 and 0.73 respectively and, for the GDPs, mean sensitivity was 0.53 and specificity 0.66. The independent T-test found a significant difference $(p<0.001)$ for both sensitivity and specificity between GDPs and the endodontists. The study also found a significant difference between the sensitivity and specificity of GDPs and their undergraduate education ( $p$-value of 0.01 and $<0.001$ respectively). GDPs also recorded a significant difference between attending continuing education courses in radiology and their specificity $(p<0.004)$. Conclusions: Endodontists were more able than GDPs in recognising apical pathology. Attending postgraduate courses in radiology interpretation increased the specificity of GDPs.
\end{abstract}

Keywords Periapical Lesion, Sensitivity, Specificity, Questionnaire

\section{Introduction}

Within clinical dental practice, dental radiography continues to provide clinicians with the ability to determination the presence or absence of periapical pathology. The radiographic examination allows the clinician to visualise the early indicators of periapical periodontitis, such as the loss of the lamina dura and widening of the periodontal ligament space ${ }^{1}$. However a number of studies have highlighted the fact that participating clinicians often show inconsistency in their ability to recognise these radiological signs which portent the presence of early inflammatory apical pathology ${ }^{2-5}$. Several research studies have been conducted in this field ${ }^{6}$. Each of these studies have highlighted the importance of a high quality radiographic examination with which to provide the clinician with the ability to accurately interpretate ${ }^{7}$ the presence of subtle changes within the periodontium which herald the onset of apical periodontitis. Moreover, the interpretation of the presence of a periapical lesion can be complicated by several factors. These have included the radiological training of the observer ${ }^{8}$.

The anatomical complexity of the tooth under consideration and, finally, the time required between the onset of symptoms and the time taken for the radiological features of apical pathosis to develop ${ }^{6}$. It was noticeable that, baring one study, each of the previously conducted studies within this field of research has relied primarily upon a small number of observers reviewing a small sample of periapical radiographs.

As such the aims of this study were twofold:

1. To investigate the ability of a large sample of both endodontic specialists and GDPs to interpret early apical pathology and

2. To ascertain whether or not the sensitivity and specificity of the observers has any relationship to any of the following factors: age, undergraduate education in radiological interpretation and attendance at postgraduate courses on radiological interpretation. 


\section{Material and Methods}

The study involved a postal questionnaire of endodontists and GDPs in the UK. The films used in the study were obtained from clinical notes of discharged patients who had previously attended the University Dental Hospital of Manchester. These patient notes were carefully scrutinised to ensure that the diagnosis of early apical pathosis was supported by the presence of a full clinical history. In addition, the clinical file had to comprise a thorough and detailed record of the clinical examination with which to support the final diagnosis of early apical periodontitis. Similarly, periapical radiographs which showed no evidence of apical pathology were also obtained from discharged patients' clinical notes with each undergoing the strict procedures as detailed previously to ensure that the radiographs chosen each displayed a normal periodontium. Finally, the radiographic quality of each analogue periapical radiograph was assessed to ensure it displayed optimal density and contrast. The final twelve films chosen for inclusion included in the study were obtained from each sextant of the maxillary and mandibular dental arches. Two consultant radiologists in Dental and Maxillofacial Radiology simultaneously examined each film to determine the presence/absence of an early periapical lesion by consensus agreement. In those cases, in which the examiners disagreed, the film was not accepted into the study. Each of the films were assessed using ideal viewing conditions comprising a standard light box $(15 \mathrm{~cm} \mathrm{x} 30 \mathrm{~cm}), \mathrm{x} 2$ magnification and subdued room lighting. Each analogue film was examined on two occasions separated by a one-week interval using identical viewing conditions on each occasion. The final group of films consisted of six periapicals displaying in one tooth the presence of early apical pathology while the remaining six films displayed teeth with no evidence of apical change.

Each radiograph was scanned (Epson 1680 Pro; Epson, America Inc) to replicate exactly the size, density and contrast of the original film. Each film was then presented in a booklet using high quality paper with each film presented to the observer with the same dimensions as the original size 2 periapical radiograph. This presentation was then reviewed by twenty-five clinicians who found no problems with the presentation and the ability to assess the periodontal status of twelve periapical radiographs. The booklet was then sent out to 170 endodontic specialists on the specialist list within the United Kingdom and also to 857 GDPs. Below each film, the clinician was asked specifically to comment on the apical status of one specific tooth on each of the twelve periapical radiographs as to whether the tooth was exhibiting evidence of a sound periodontium or exhibiting evidence of early apical pathology.

In addition, details of age, whether or not their undergraduate course had included a formal course of radiographic interpretation and finally whether or not they had attended a post graduate course in radiographic interpretation. The data obtained was entered into a statistical work package (SPSS system). The sensitivity and specificity of each observer was measured as was the mean sensitivity and specificity. The independent samples t-test was used to evaluate whether or not there was a significant difference between the GDPs and endodontists in relation to sensitivity and specificity. The Mann-Whitney U test was used to assess if there was a significant difference between the sensitivity/specificity of the observers within their age group, undergraduate education and attendance at postgraduate radiographic interpretation courses. The relationship between sensitivity/specificity and age in years was assessed by a correlation coefficient.

\section{Results}

A total of $603(70.4 \%)$ GDPs and 132 (77.6\%) endodontists responded. The mean sensitivity and specificity for endodontists was $65 \%$ and $73 \%$ respectively. For GDPs, the mean sensitivity and specificity was $53 \%$ and $66 \%$ respectively (Fig 1, Tables 1 and Table 2).

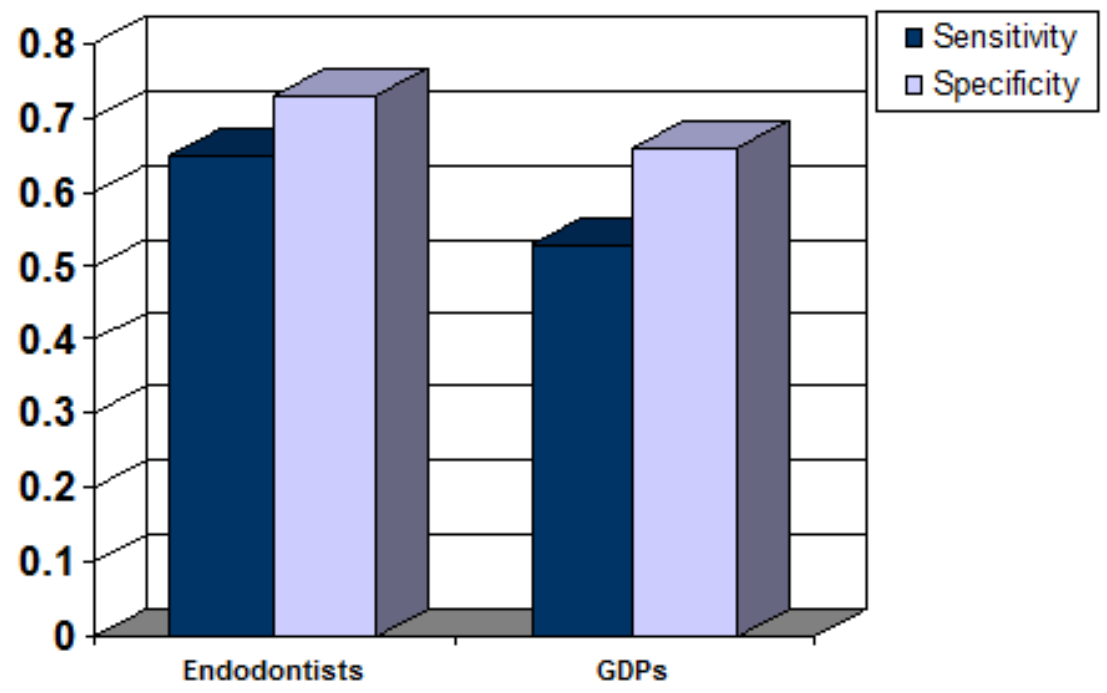

Figure 1. The mean sensitivity and specificity for endodontists and GDPs 
Table 1. Sensitivity of endodontists and GDPs

\begin{tabular}{|c|c|c|c|c|c|}
\hline \multirow{2}{*}{ Respondents } & \multirow{2}{*}{$\mathrm{N}$} & \multirow{2}{*}{ Mean } & \multirow{2}{*}{ Deviation } & \multicolumn{2}{|c|}{$\begin{array}{c}95 \% \text { confidence } \\
\text { limit }\end{array}$} \\
\cline { 5 - 6 } & & & & Lower & Upper \\
\hline Endodontists & 132 & 0.65 & 0.183 & 0.616 & 0.679 \\
\hline GDPs & 603 & 0.54 & 0.172 & 0.522 & 0.549 \\
\hline
\end{tabular}

Table 2. Specificity of endodontists and GDPs

\begin{tabular}{|c|c|c|c|c|c|}
\hline \multirow{2}{*}{ Respondents } & \multirow{2}{*}{$\mathrm{N}$} & Mean & $\begin{array}{c}\text { Std } \\
\text { Deviation }\end{array}$ & \multicolumn{2}{|c|}{$\begin{array}{c}\text { 95\% confidence } \\
\text { limit }\end{array}$} \\
\cline { 5 - 6 } & & & & Lower & Upper \\
\hline Endodontists & 132 & 0.73 & 0.195 & 0.699 & 0.766 \\
\hline GDPs & 603 & 0.66 & 0.188 & 0.649 & 0.679 \\
\hline
\end{tabular}

The independent sample t-test showed a significant difference $(p<0.001)$ for both sensitivity and specificity between GDPs and endodontists (Table 3).

Table 3. Independent sample t-test for the sensitivity and specificity of endodontists and general dental practitioners

\begin{tabular}{|c|c|c|c|c|c|}
\hline \multirow{2}{*}{ Test } & \multirow{2}{*}{$\mathrm{t}$} & \multirow{2}{*}{$\begin{array}{c}\text { Mean } \\
\text { difference }\end{array}$} & \multicolumn{2}{|c|}{$\begin{array}{r}\text { 95\% confidence } \\
\text { limit }\end{array}$} & \multirow{2}{*}{ P-value } \\
\cline { 4 - 5 } & & & Lower & Upper & \\
\hline Sensitivity & 6.698 & 0.112 & 0.0791 & 0.145 & $<0.001$ \\
\hline Specificity & 3.737 & 0.0678 & 0.0322 & 0.1035 & $<0.001$ \\
\hline
\end{tabular}

For both groups, values for sensitivity and specificity increased with age. When undergraduate radiology training was considered, there was a difference between the two groups. For endodontists, the undergraduate training received in radiological interpretation had no significance on their ability to detect apical pathosis. The converse was found for GDPs (sensitivity $p=0.01$; specificity $p<0.001$ ). In addition, attendance at postgraduate radiology courses had no significance for endodontists. However, GDPs recorded a significant difference between attending continuing education courses in radiology and specificity $(p=0.004)$.

\section{Discussion}

The literature reveals that a number of studies have been undertaken within this field of research. These have employed different methodologies ranging from consensus amongst participating clinicians $5,9,10,11,12$ to confirm evidence of early apical change. Other studies did not include healthy patient radiographs in the sample ${ }^{13,14}$. However, in the study conducted by Bohay, both diseased and healthy teeth were included ${ }^{6}$. Previous studies ${ }^{5,6}$ have looked at the diagnostic accuracy of observers using analogue films to determine the sensitivity and specificity for periapical change among a number of observers. There was only one study which was conducted by Stheeman and colleagues ${ }^{15}$ in which 98 GDPs interpreted duplicated conventional radiographs and the sensitivity and specificity were also assessed. However, there are no published reports in a large-scale study by which the performances of GDPs and endodontists in interpretation of an early periapical pathosis were compared. Periapical radiographic examination is one of the most frequently used diagnostic tests in endodontics for identification of periapical lesion. Several researchers ${ }^{5,9,11}$ have evaluated the diagnostic performance of periapical radiography exclusively depending on radiographs to determine, by consensus, true positive and true negative cases. In this study, the method of determining the presence or absence of early periapical lesion, including consensus selection by proficient examiners ${ }^{16}$ followed by repeat evaluation to role out any indefinite diagnoses, was considered the most probable technique ${ }^{11}$. It is assumed that by using this method, the likelihood of incorrect diagnosis was significantly minimised. A microscopic evaluation of the health or disease of periapical tissues is considered the ideal gold standard ${ }^{5}$. However, within the United Kingdom, this option is not always feasibly done in clinical situations.

A combination of clinical indication and radiographic evidence of periapical changes is often required to reach an accurate diagnosis of a periapical pathosis. In this study, the consensus agreement of the two expert radiologists on the radiographic evidence of early periapical lesion was dependent on reviewing thorough clinical records taken into account important indicators and clinical signs of periapical infection such as a negative response to vitality tests and tenderness to percussion. The use of complete clinical assessment from the patient's notes in the assessment of the status of teeth has been previously used by other authors ${ }^{5,12}$. Bohay ${ }^{6}$ noted that the use of complete clinical records may minimise the risk of bias within a research study.

An alternative method to determine the gold standard could have been used by means of a prospective clinical study on teeth that were to be extracted. Although this method has its advantages, it remains the complexity of obtaining the histopathological diagnosis because of the possibility of tooth extraction can disrupt the periodontal ligament space and subsequently the pathology associated with it. Alternatively, a more appropriate study design could have included radiographs of teeth from cadaver jaws followed by sectioning and histological analysis of each tooth's periapical tissues to determine a gold standard diagnosis ${ }^{11}$. This avenue of research was also found to be unfeasible.

It has been demonstrated that radiographic appearance of an early or small periapical lesions can exhibit a widened periodontal ligament space with an intact lamina dura external to the radiolucent space ${ }^{17}$. In contrast, a large periapical lesion may be presented with a complete or partial loss of the lamina dura. The current study utilised a selection of radiographs of teeth with early evidence of periapical lesions. While it is generally accepted that identification of a relatively large periapical lesion can be a straightforward diagnostic task, a diagnosis of a smaller lesion with subtle changes in the periapical tissues can be more challenging ${ }^{11}$.

The current study determined the percentage of sensitivity, and specificity of endodontists and GDPs to recognise early periapical lesions on high quality images of duplicated 
conventional radiographs. Sensitivity and specificity are frequently reported and easily understood measures of diagnostic performance of a specific test. Sensitivity is the ability of a diagnostic test to accurately identify patients who truly have disease. Specificity is the ability of the diagnostic test to accurately identify patients who do not have the disease. As far as an early periapical lesion diagnosis is concerned; Wallace and colleagues ${ }^{18}$ stated that the detection of these lesions is a challenging one, although not impossible task. Patel et $\mathrm{al}^{11}$ argued that specificity of observers is more important than sensitivity. While poor sensitivity can in worst scenarios result in overlooking a sign-free periapical lesion and subsequently being detected when becomes symptomatic or larger in size, deficiencies in specificity measure may lead to more serious consequences such as performing an unnecessary endodontic treatment. Generally, as sensitivity increases, specificity will decrease and the opposite is true ${ }^{6}$. Tests such as sensitivity and specificity are most appropriately used to ascertain the presence of a disease that have been diagnosed using other clinical findings ${ }^{19}$. The present study found that the mean specificity of both endodontists and GDPs in the diagnosis of an early periapical lesion were higher than the sensitivity. For endodontists, the mean sensitivity and specificity of periapical diagnosis were 0.64 and 0.73 respectively. The corresponding values for GDPs were 0.53 and 0.66 respectively. Based on these values, it can assumed that by using periapical radiographs to diagnose an early apical pathosis, $36 \%$ and $47 \%$ of individuals with disease could be missed by endodontists and GDPs respectively. On the other hand, $27 \%$ and $34 \%$ of patients could be incorrectly diagnosed with periapical lesion by endodontists and GDPs respectively.

The results of this study showed an overall level of sensitivity and specificity which can be considered comparable to previous studies. For example, Stheeman et $\mathrm{al}^{15}$ reported an overall sensitivity and specificity for detection of periapical lesions of $59 \%$ and $61 \%$ respectively. On the other hand, higher values were reported by Tammisalo and co-workers ${ }^{13}$ who reported a level of sensitivity of $70 \%$ and a level of specificity of $90 \%$, and Patel et $\mathrm{al}^{11}$ with an equal percentage for sensitivity and specificity of $78 \%$. Moreover, Bohay ${ }^{6}$ found that the specificity of observer to recognise apical pathosis was $78 \%$ and $65 \%$ for sensitivity. Sullivan and colleagues ${ }^{20}$ reported a range of sensitivity from $33 \%$ to $85 \%$ depending on the size of the lesion and specificity of $56 \%$.

Although the radiographs selection was carried out by a consensus agreement of two expert consultant radiologists to ensure the adequacy of the images diagnostic quality and clarity, this study can be criticised for not permitting the participants to use ideal viewing conditions such as viewing box, masking and magnification for radiographic evaluation. However, Szymkoviak et $\mathrm{al}^{21}$ found that $40 \%$ of practitioners always viewed radiographs without the benefit of light box, so the method employed in this study replicate normal viewing conditions for practitioners in dental office. Other alternative methods of presenting the radiographs were the use of high-resolution scanned radiographs to allow the images to be displayed on a monitor in the practitioner's surgery, or possibly sending out duplicated images which could be viewed within the practice either using a viewing box or just by holding the radiograph against a light source. However, it was thought that adopting the latter would have introduced too many variables and a decision was made to standardise the viewing conditions by employing high-definition photographs.

Comparison between endodontists and GDPs is often overlooked when radiographic diagnostic performance of observers is considered. There is no published data concerning a comparison of the diagnostic accuracy of a large sample of GDPs and endodontists to interpret an early periapical lesion. In this study, two groups (endodontists and GDPs) of observers were selected. These observers had graduated from different dental schools with different experience backgrounds but had adequate preliminary radiographic education and training. Many studies $3,4,12,22,23$ have previously reported using clinicians with a varying range of clinical experience, as with the current study. It was well documented by many authors that observer experience may influence the radiographic interpretation of early periapical pathosis $5,20,24,25$

Unsurprisingly, this study demonstrated higher levels of sensitivity and specificity for endodontists than the GDPs. It could be argued that the differences between groups might be explained by the use of group of non-calibrated examiners, and that better results could be achieved if training and calibration of GDPs was employed ${ }^{26}$. However, this was obviously difficult to address owing to the large sample size and the employed design of such a questionnaire-based survey.

Several studies have shown that factors such as dentists' age and attendance of postgraduate courses can influence their radiographic practice ${ }^{27-29}$. In the current study, a positive correlation was found between measures of accuracy and age of observers. As age increased the sensitivity and specificity of observers increased, however, the difference was statistically significant only between the specificity and the age of GDPs cohort. This finding could be explained by the fact that older practitioners are expected to be more experienced in identification of early periapical lesion owing to the number of years of practice the higher number of cases performed. Furthermore, this survey found that the sensitivity and specificity of GDPs increased with attending a radiographic interpretation course. Results of this study also suggested that there was a significant association between the undergraduate dental education and the ability of GDPs to recognise the presence or absence of periapical lesion while the undergraduate education of endodontists had no bearing on their diagnostic performance. A possible hypothesis to explain this finding is that the endodontist's experience in radiographic interpretation is often not dependent on undergraduate education and more likely gained by either postgraduate courses or clinical experience 
in endodontic practice.

\section{Conclusions}

Endodontists were more able than GDPs in recognising apical pathology. Attending postgraduate courses in radiographic interpretation increased the specificity of GDPs.

\section{Acknowledgements}

The author would like to express her gratitude to Professor Keith Horner, the University of Manchester, for his assistance in co-assessing the apical status of the films used in this study and to Professor Helen Worthington, the University of Manchester, for her assistance with the statistical analysis.

\section{Copy of the Questionnaire}

Please view the radiographs below and indicate whether you feel that there is apical pathology. Please circle as appropriate:

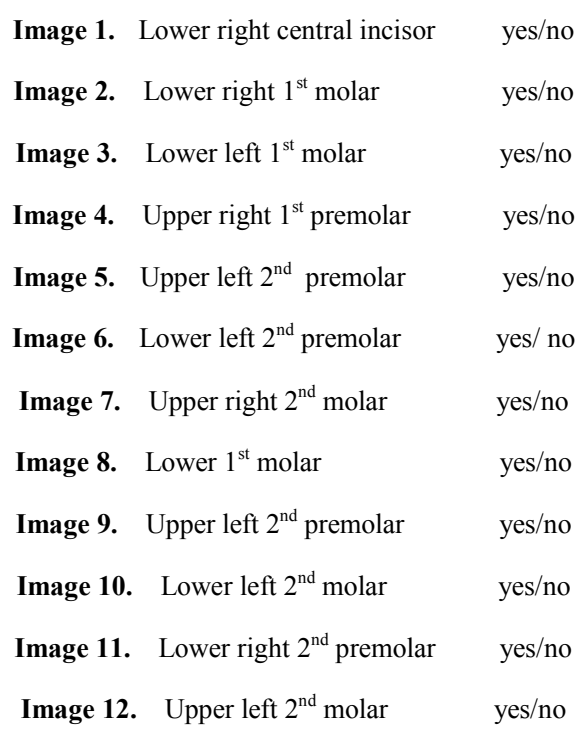

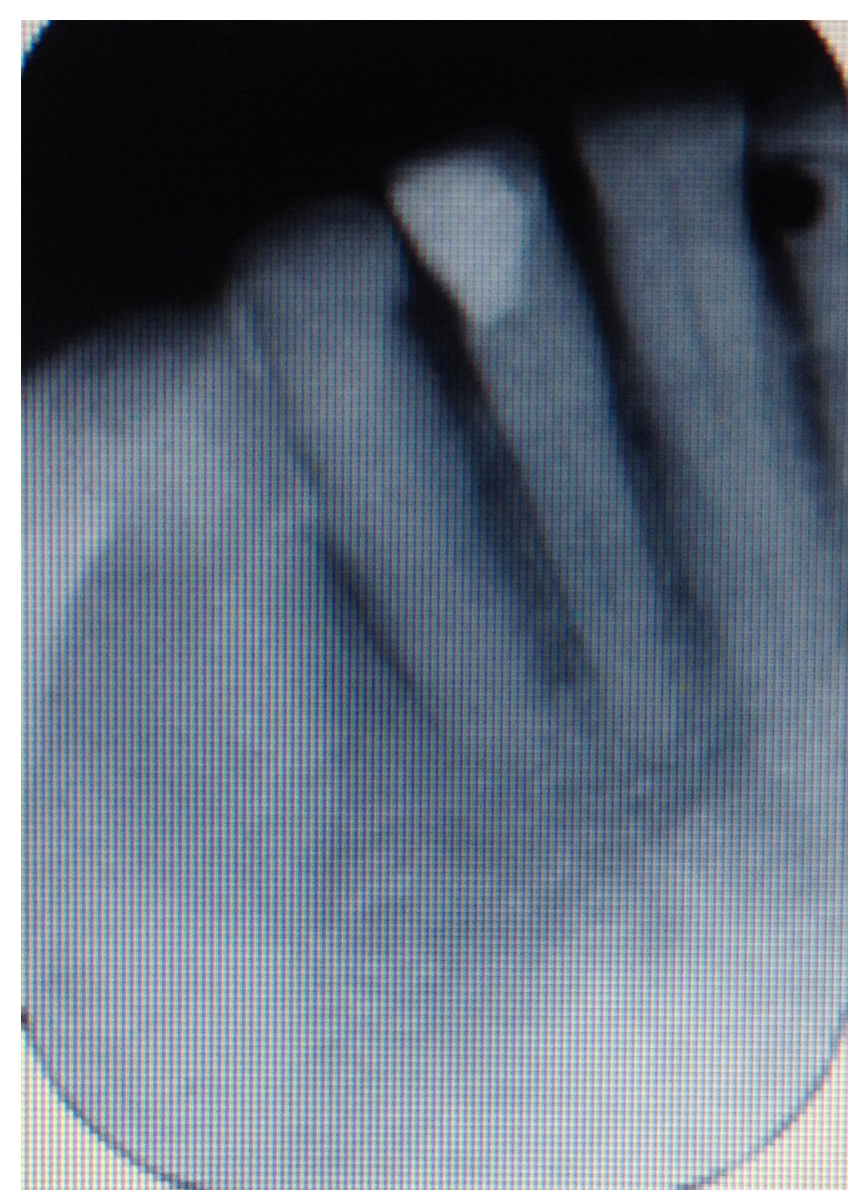

Image 1. Lower right central incisor

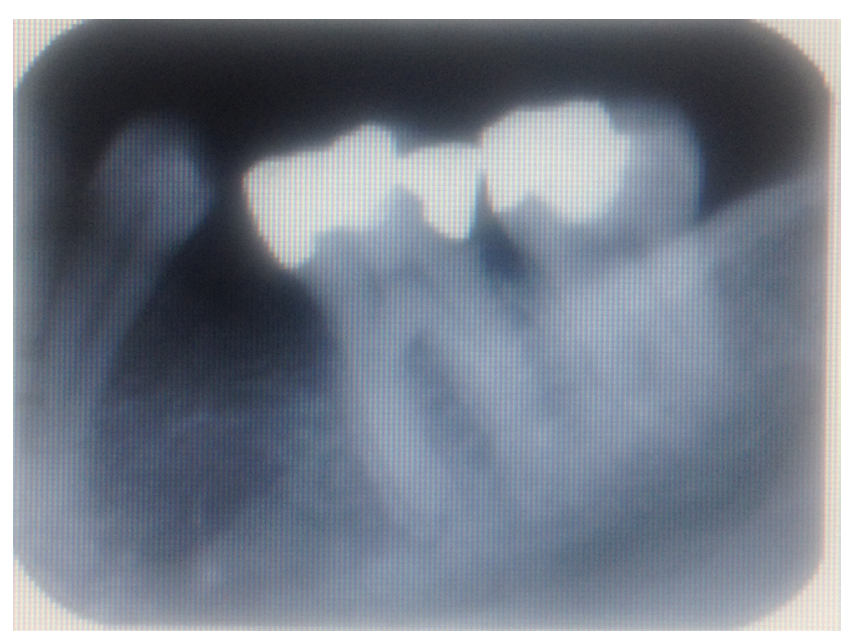

Image 2. Lower right $1^{\text {st }}$ molar 


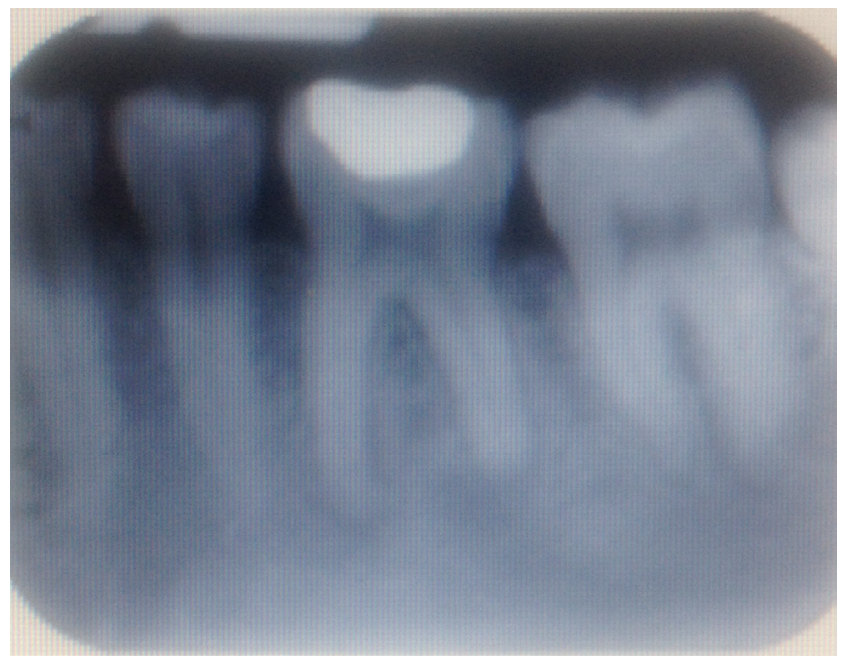

Image 3. Lower left $1^{\text {st }}$ molar

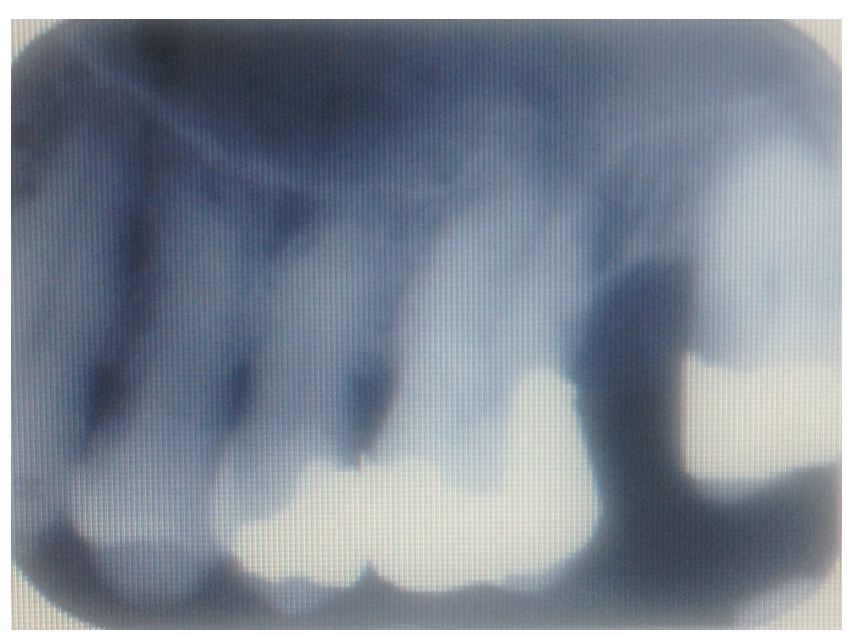

Image 4. Upper right $1^{\text {st }}$ premolar

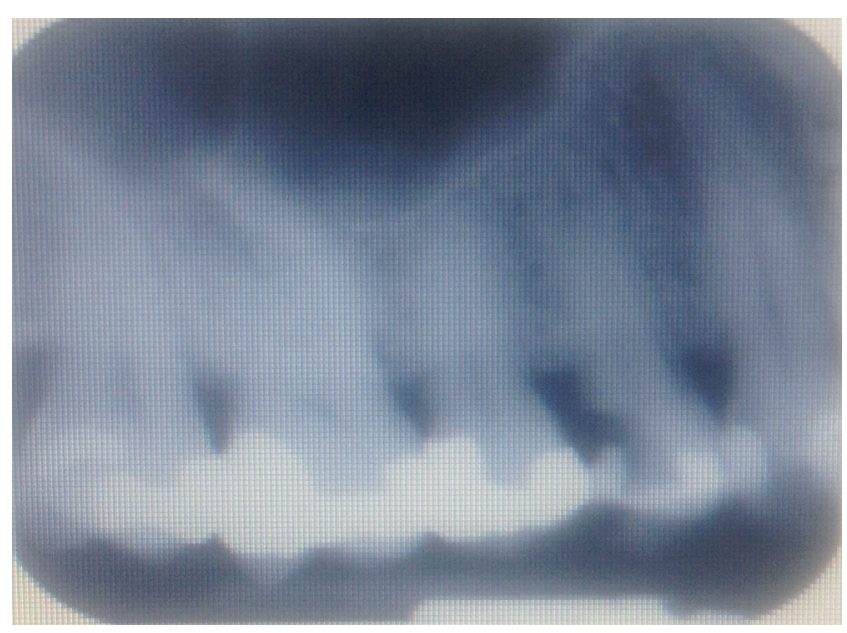

Image 5. Upper left $2^{\text {nd }}$

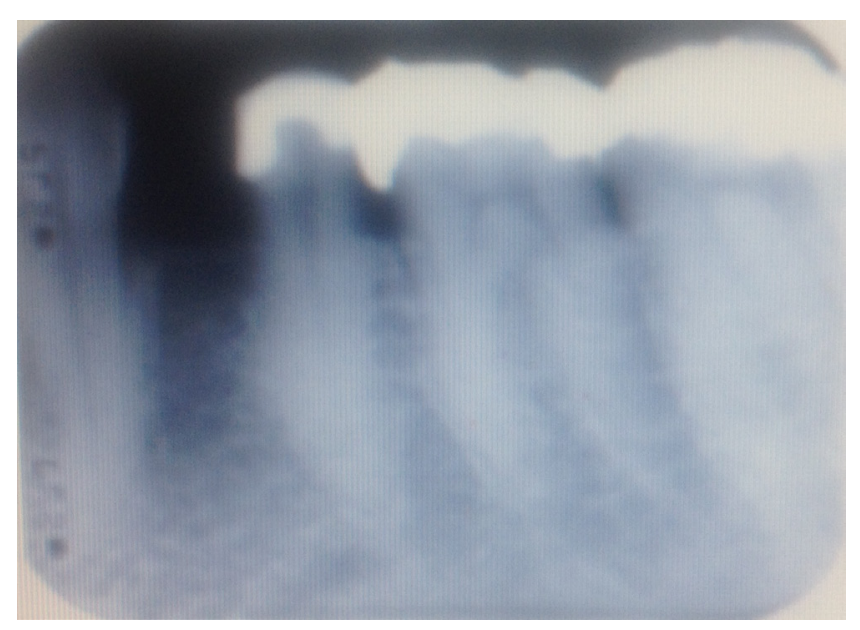

Image 6. Lower left $2^{\text {nd }}$ premolar

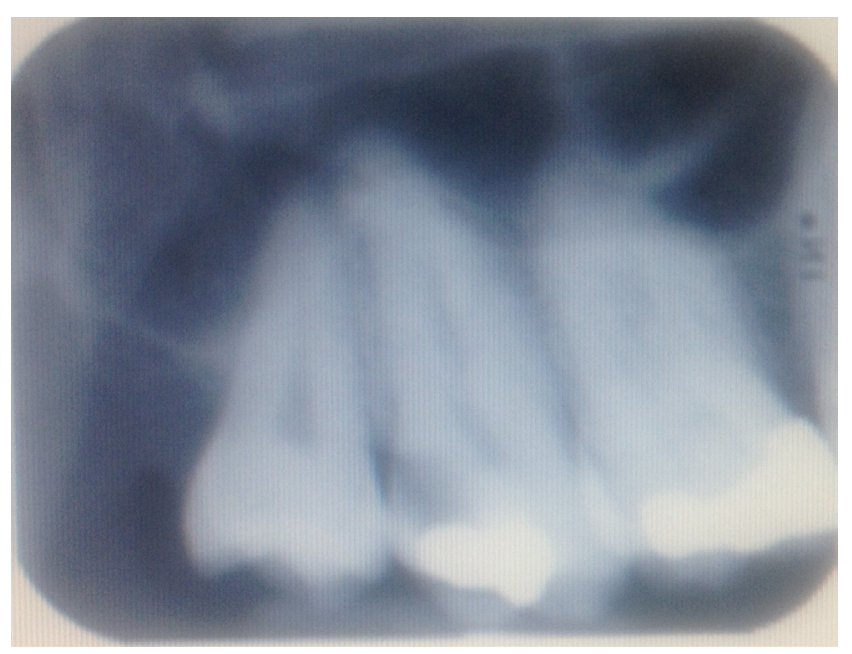

Image 7. Upper right $2^{\text {nd }}$ molar

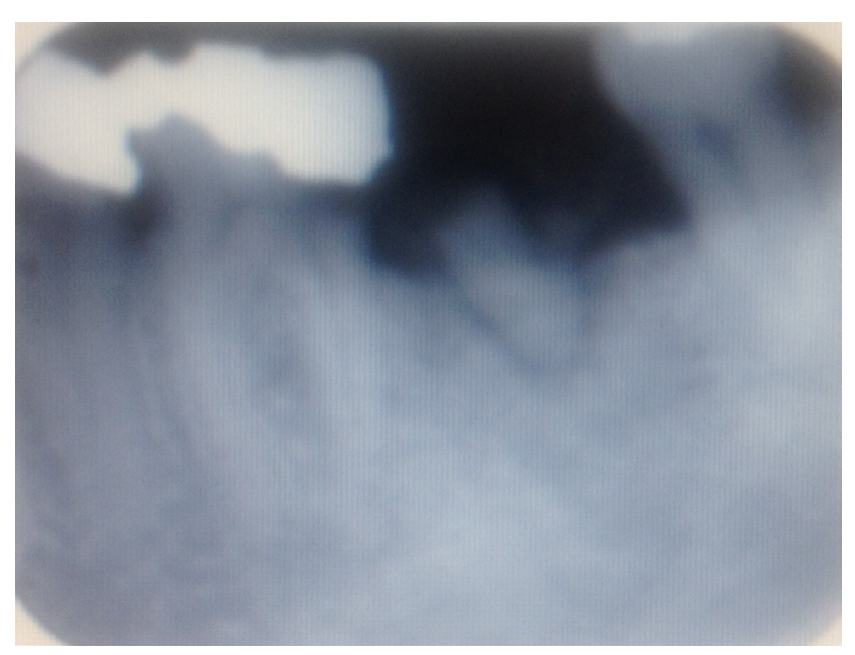

Image 8. Lower $1^{\text {st }}$ molar 


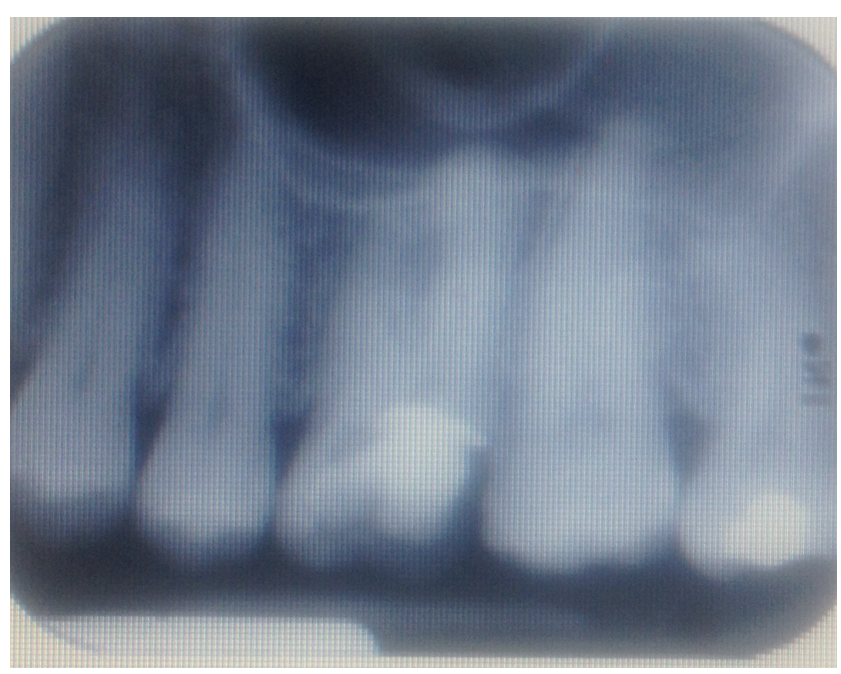

Image 9. Upper left $2^{\text {nd }}$ premolar

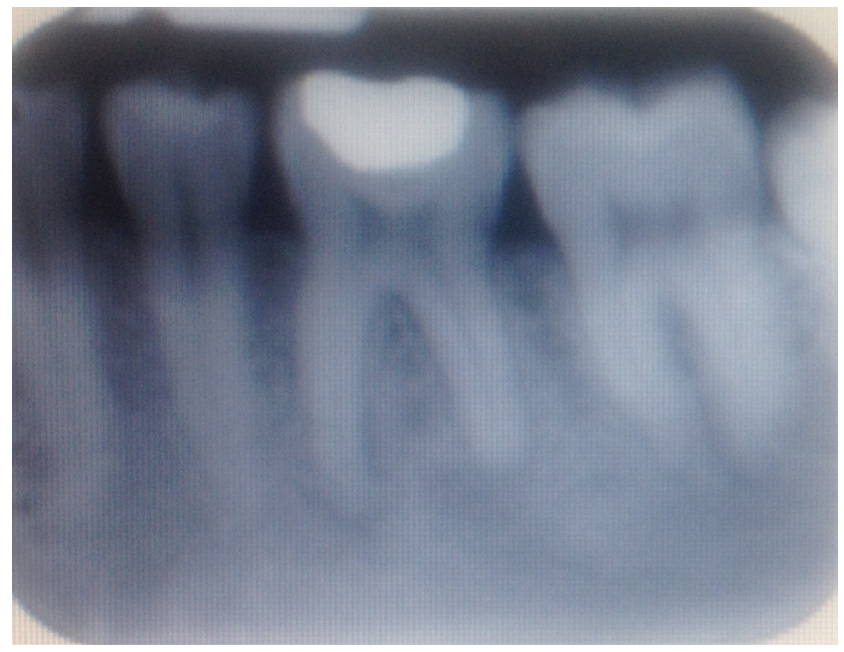

Image 10. Lower left $2^{\text {nd }}$ molar

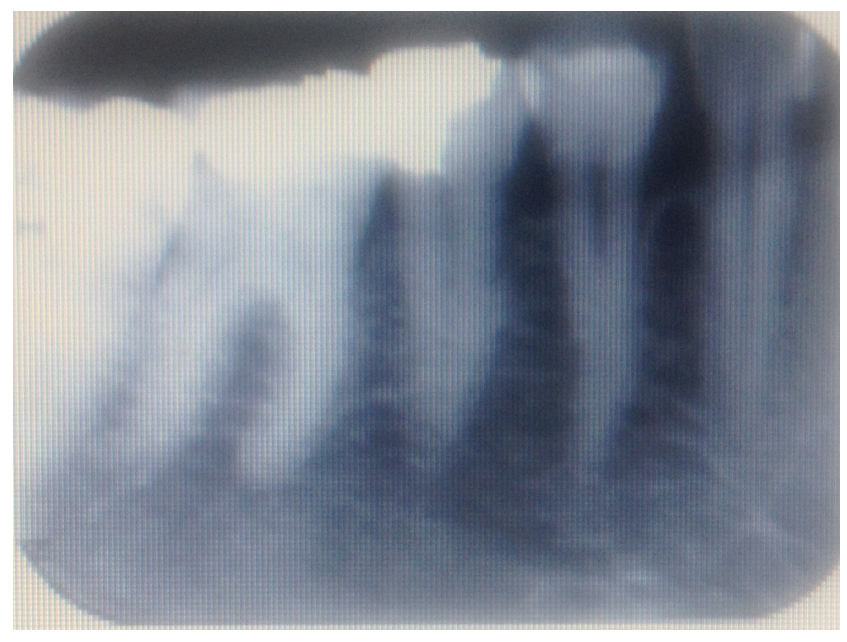

Image 11. Lower right $2^{\text {nd }}$ premolar

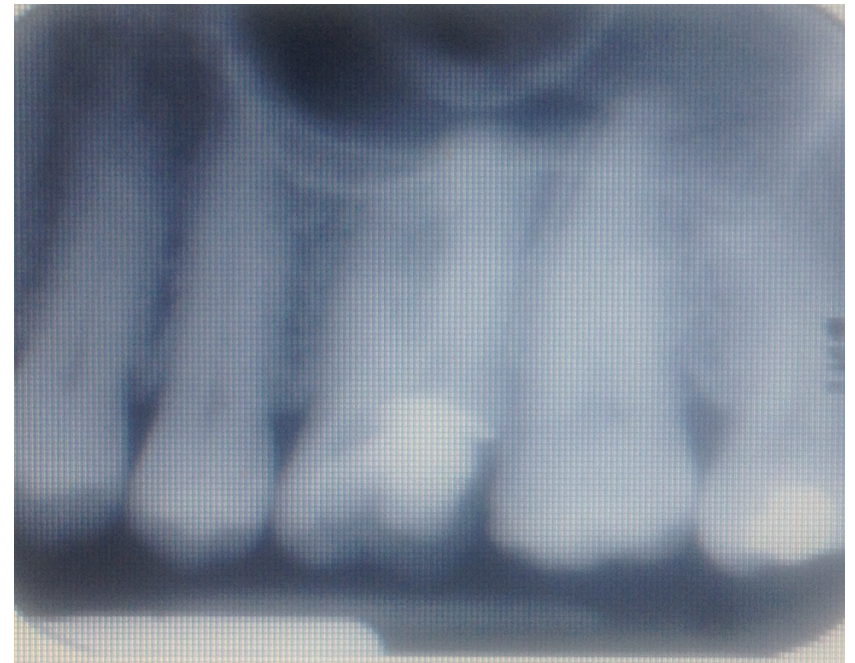

Image 12. Upper left $2^{\text {nd }}$ molar

Thank you for your time in completing this questionnaire.

\section{REFERENCES}

[1] Lee L. Inflammatory lesions of the jaws. In White SC,Pharoah MJ (ed). Oral Radiology: Principles and Interpretation, 5th ed. pp.338-354.. St Louis, MO, USA: CV Mosby, 2006.

[2] Goldman M, Pearson AH, Darzenta N. Endodontic success--who's reading the radiograph? Oral Surg, Oral Med, and Oral Path 1972; 33:432-437.

[3] Goldman M, Pearson AH, Darzenta N. Reliability of radiographic interpretations. Oral Surg, Oral Med, and Oral Path. 1974; 38: 287-293.

[4] Reit C and Hollender L. Radiographic evaluation of endodontic therapy and the influence of observer variation. Scand J Dent Res 1983; 91: 205-212.

[5] Abdel-Wahab M, Greenfield T, Swallow J. Interpretation of intraoral periapical radiographs. $J$ Dent $1984 ; 12,302-313$.

[6] Bohay RN. The sensitivity, specificity, and reliability of radiographic periapical diagnosis of posterior teeth. Oral Surg, Oral Med, Oral Path, Oral Rad and Endo 2000; 89: 639-642.

[7] Cohen A, Burns R. Pathway of the Pulps 2002. St Louis: Mosby.

[8] Lanning SK, Best AM, Temple HJ, Richards PS, Carey A, Mccauley LK Accuracy and consistency of radiographic interpretation among clinical instructors in conjunction with a training program. J Dent Educ 2006; 70: 545-557.

[9] Molander B, Ahlqwist M, Grondahl HG. Panoramic and restrictive intraoral radiography in comprehensive oral radiographic diagnosis. Eur J of oral sci 1995; 103:191-198.

[10] Rohlin M, Akerblom A. Individualized periapical 
radiography determined by clinical and panoramic examination. Dentomaxillofac Radiol 1992; 21: 135-141.

[11] Patel N, Rushton VE, Macfarlane TV, Horner K. The influence of viewing conditions on radiological diagnosis of periapical inflammation. Br Dent J 2000; 189: 40-42.

[12] Rushton VE, Qualtrough A J, Al-Masserah Y, Rushton MN. The influence of coronal tooth tissue in the diagnosis of apical pathosis. Int Endo J 2009; 42:603-608.

[13] Tammisalo T, Luostarinen T, Vahatalo K, Neva M. Detailed tomography of periapical and periodontal lesions. Diagnostic accuracy compared with periapical radiography. Dentomaxillofac Radiol 1996; 25: 89-96.

[14] Mol A , Van Der Stelt PF. Application of computer-aided image interpretation to the diagnosis of periapical bone lesions. Dentomaxillofac Radiol ; 21: 190-194.

[15] Stheeman SE, Mileman PA, Van' T Hof M, Van Der Stelt PF. Room for improvement? The accuracy of dental practitioners who diagnose bony pathoses with radiographs. Oral Surg, Oral Med, Oral Path, Oral Rad and Endo 1996; 81: 251-254.

[16] Mileman PA, Van Der Weele LT. Accuracy in radiographic diagnosis: Dutch practitioners and dental caries. J Dent. 1990; 18: $130-136$.

[17] Pitt Ford TR. The radiographic detection of periapical lesions in dogs. Oral Surg Oral Med and Oral Path. 1984; 57: 662-667.

[18] Wallace JA, Nair MK, Colaco MF, Kapa SF. A comparative evaluation of the diagnostic efficacy of film and digital sensors for detection of simulated periapical lesions. Oral Surg, Oral Med, Oral Path, Oral Rad and Endo 2001; 92:93-97.

[19] Fletcher R, Fletcher S, Wagner E. Clinical epidemiology the essentials 1988. 2nd ed. Baltimore: Williams and Wilkins.
[20] Sullivan JE Jr, Di Fiore PM, Koerber A. Radiovisiography in the detection of periapical lesions. J Endo 2000; 26: 32-35.

[21] Szymkowiak LE, Sarll DW, Horner K. Some factors affecting the standards of radiography in general dental practice. $\mathrm{Br}$ Dent J 1995; 179: 168-174.

[22] Reit C, Hollender L. Radiographic evaluation of endodontic therapy and the influence of observer variation. Scand J Dent res 1983; 91: 205-212.

[23] Makdissi J. Interpretation of dental and maxillofacial radiographs: a comparative study using an X-ray viewing box and window. J Ir Dent Ass 2002; 48:123-124.

[24] Grondahl HG. Some factors influencing observer performance in radiographic caries diagnosis. Swed Dent $J$ 1979; 3: 157-172.

[25] Mccaul LK, Mchugh S, Saunders WP. The influence of specialty training and experience on decision making in endodontic diagnosis and treatment planning. Inter Endo $J$ 2001; 34: 594-606.

[26] Reit C, Grondahl HG Application of statistical decision theory to radiographic diagnosis of endodontically treated teeth. Scand J Dent research 1983; 91, 213-218.

[27] Bohay RN, Kogon SL , Stephens RG. A survey of radiographic techniques and equipment used by a sample of general dental practitioners. Oral Surg Oral Med and Oral Patho 1994; 78: 806-810.

[28] Svenson B, Soderfeldt B , Grondahl HG. Attitudes of Swedish dentists to the choice of dental X-ray film and collimator for oral radiology. Dentomaxillofac Radiol 1996; 25: $157-161$.

[29] Tugnait A, Clerehugh V, Hirschmann PN. Radiographic equipment and techniques used in general dental practice: a survey of general dental practitioners in England and Wales. $J$ Dent 2003; 31:197-203. 